\title{
Entre raça e classe: os desafios de se pensar a etnicidade na América Latina
}

\author{
Between race and class: the challenges of the concept \\ of ethnicity in Latin America
}

\author{
Carlos Henrique Assunção Paiva \\ Pesquisador da Casa de Oswaldo/Fiocruz - OPAS/OMS \\ Av. Brasil, 4036/sala 414 - Manguinhos \\ 21040-361 Rio de Janeiro - RJ - Brasil \\ cpaiva@coc.fiocruz.br
}

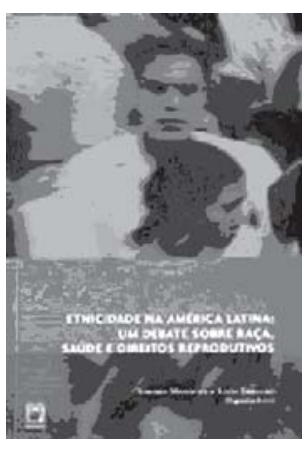

Monteiro, Simone; Sansone, Livio Etnicidade na América Latina: um debate sobre raça, saúde e direitos reprodutivos. Rio de Janeiro: Ed. Fiocruz, 2004. 344 p.
F tnicidade na América Latina: um debate sobre raça, saúde e direitos reprodutivos, E organizado por Simone Monteiro e Livio Sansone, é um trabalho precursor que reúne não apenas contribuições acadêmicas strictu sensu, mas também textos de personagens dos movimentos sociais ligados ao tema. Este dado torna o livro por si só uma referência importante, pois ele não apenas representa uma contribuição interessante àqueles inspirados unicamente na discussão teórica, mas também constitui indicação relevante para aqueles mais dispostos a pensar políticas públicas capazes de lidar com problemas ligados à saúde e aos direitos reprodutivos. Nesse ponto, de início, é interessante sinalizar que o livro faz de sua aparente fragilidade a sua maior fortaleza. Imagine-se reunir, sob a batuta de um tema cercado de paixões ideológicas, pensadores e militantes de diversas tonalidades e formações!

Trata-se, assim, de um trabalho composto por textos de inegável riqueza metodológica e teórica, argumentos diversos, bem como fontes de pesquisa variadas, que servem de apoio aos quinze artigos, divididos em quatro eixos temáticos. A partir de agora passarei a comentar rapidamente a estrutura geral do livro, acentuando aqui e ali algumas questões particulares de meu interesse.

A primeira parte do livro discute o tema saúde e etnicidade em um tom marcadamente histórico. É o que se vê especialmente no artigo de abertura, "Raça, doença e saúde pública no Brasil: um debate sobre o pensamento higienista do século XX", de Marcos Chor Maio. Nele, o sociólogo se vale do trabalho do historiador Sidney Chalhoub para trazer à tona importante debate historiográfico, cujo foco é a interpretação do papel e da atuação da medicina e dos médicos, de suas relações com o establishment nacional na virada do século XIX para o século XX. Chalhoub, mais alinhado com a perspectiva que sugere um papel da medicina no controle dos corpos e na formação de um capitalismo brasileiro, procura demonstrar um forte pensamento racista no campo médico nacional. Visão que, a meu ver, Maio competentemente combate, revelando determinadas ciladas teóricas, que apontam, por sua vez, para ausência, ainda hoje, de pesquisas de cunho acentuadamente histórico (em que pese a importante literatura já consagrada pelo tema, que Maio coloca ao seu lado). Dessa forma, o autor entende que durante as primeiras décadas do século $\mathrm{XX}$ ocorrem, num só tempo, uma ruptura e uma continuidade históricas com relação a essa temática. Uma 
ruptura com relação ao ideário marcadamente racialista da segunda metade do século XIX, quando encontramos figuras como o médico Raimundo Nina Rodrigues; mas também uma continuidade, embora sob os novos moldes da bacteriologia e da microbiologia, em que se retomou a visão neo-hipocrática do século XIX.

Para o bem da verdade, Maio não procura ausentar os interesses econômicos como elementos analíticos importantes nos rumos da institucionalização da ciência médica no país, mas sim considera que a existência desses interesses não invalida outras possibilidades interpretativas.

Já o trabalho de Simone Monteiro passa em revista a literatura que reflete sobre a forma como as condições sócio-econômicas interagem com aspectos culturais e biológicos, de forma a produzir desigualdades no campo da saúde que possam ser interpretadas em termos étnicoraciais. Trata-se de uma questão da maior importância, visto que muitas vezes o que percebemos são visões reducionistas a respeito das diferenças raciais, de tal forma que no final das contas se acaba por ratificar o racismo, ao se enfatizarem possíveis diferenças biológicas irredutíveis (isto é, aquém ou fora de contato com as diretrizes sócioambientais). Ao fazer isto, Monteiro também aponta para a necessidade de desenvolvimento de novas metodologias capazes de lidar com variações etno-raciais que possam permanecer despercebidas nas análises epidemiológicas.

$\mathrm{Na}$ esteira do capítulo anterior, o texto de Livio Sansone faz refletir, mediante interessantíssimo estudo de caso no México, na Nicarágua e na Colômbia - fazendo jus até mesmo ao título da coletânea -, sobre as relações entre classe social, raça e saúde reprodutiva na América Latina. Embora o autor esclareça a falta de dados relevantes, que permitam inferir conclusões mais acabadas acerca do tema, é bom que se diga que a construção de seus argumentos é bastante esclarecedora, especialmente quando chama atenção para as agudas diferenças nacionais acerca do debate e das experiências sobre etnicidade/raça.

A segunda parte do trabalho, "Etnicidade e saúde", inaugura um franco debate entre os diversos autores da coletânea - fragmento este que reflete em boa medida um trabalho organizado a partir de um evento. Nesse contexto, o trabalho de José Carlos dos Anjos serve como um verdadeiro abre-alas no ambiente de debate construído juntamente com os artigos seguintes. Seguindo os passos do filósofo francês Michel Foucault, o autor procura construir argumentos teóricos em uma perspectiva autodenominada historicista nominalista, em que o conceito de raça é instrumentalizado como uma ferramenta de construção e disseminação de poder sobre os corpos que, ao serem tratados como potencialmente saudáveis, seriam ao mesmo tempo capitalizados como forças produtivas do Estado-nação.

As críticas a esse argumento partem do debate que os textos seguintes estabelecem com o trabalho de Anjos, especialmente o interessante texto de Peter Fry. O argumento deste antropólogo é que a adoção do modelo bi-racial, inspirado no modelo norte-americano, põe como ordem do dia - contraditoriamente, diríamos - uma retomada de velhos paradigmas racistas. Por isto, o texto de Fry é completamente desafia- 
dor a determinadas premissas dos movimentos sociais ligados aos negros. Isto sem falar em problema latente e patente durante todo o livro: a necessidade de maior refinamento conceitual na utilização da raça/etnia como variável explicativa. O que vemos em maior grau no senso comum, mas ainda na academia, é uma confusão brutal entre raça/etnia e classe, de modo que este último aspecto sociológico se vê absolutamente tratado como demarcador racial (pobre, negro...). Isso, como o demonstra o texto de Fry, pode significar ironicamente uma importante pauta de afirmação do racismo - isto é, de diferenças biológicas irredutíveis.

O trabalho de Mara Viveros Vigoya retoma os argumentos do trabalho de J. C. dos Anjos, de maneira a se alinhar às propostas deste autor e talvez radicalizá-las, pois em seu texto há até mesmo certa diabolização da medicina, como estratégia foucaultiana de poder. Nesse caso, de certa maneira, os textos de Fry e de Maio servem como excelentes contrapontos desta perspectiva teórica, que, a meu ver, carece ainda de maior embasamento empírico.

A terceira parte, "Saúde reprodutiva e população indígena", nos expõe um tema ainda pouco explorado pela literatura, se comparado àqueles relacionados ao negro, grupo normalmente privilegiado quando se trata de pesquisas de recorte étnico. Assim, o primeiro trabalho dessa sessão, de Carlos E. A. Coimbra e Luiz Garnelo, propõe três recortes de investigação sobre o tema: a) a relação entre a saúde reprodutiva e a dinâmica demográfica; b) o perfil epidemiológico ligado à saúde reprodutiva; e c) fatores sócio-culturais relacionados à saúde reprodutiva.

Os demais artigos dessa sessão não seguiram caminho inteiramente diferente daquele apresentado pelo artigo de Coimbra e Garnelo. Mas cabe chamar atenção aqui ao belo artigo de Renato Athias que, em uma perspectiva antropológica, procurou tratar da área indígena Pankararu, a cerca de 500 quilômetros de Recife, para pontuar determinadas particularidades e, assim, sinalizar para a dificuldade de tratamento do índio como unidade homogênea de análise. E Esther Langdon, na mesma sessão, procurará de alguma forma se contrapor a ele, ao propor maior nível de generalização a partir dos argumentos de Athias. De certa forma, algo que permite determinada unidade aos artigos dessa sessão se dá pela ausência de dados disponíveis à análise, isto sem falar na literatura ainda escassa. Este elemento delimitador apenas chama a atenção para o caráter precursor destas investigações, pois, mesmo diante da dificuldade de validação da pesquisa em dados empíricos, confiáveis ou não, aqueles apresentados são capazes de não apenas sustentar suas argumentações, como também apontar direções e rumos tanto para as novas pesquisas, como para as políticas de saúde.

A última parte, "Saúde reprodutiva e população negra", abre-se com o trabalho de André Caetano, que afirma, com base em dados estatísticos refinados, que a população negra se vê no país mais afetada pela prática da esterilização, se comparada aos demais grupos étnicos. Esta hipótese, em perfeita sintonia com a discussão de toda a obra, é tratada mais teoricamente no texto seguinte, de Francisco Bastos, que 
procurou demonstrar certa rejeição de 'raça' como uma categoria explicativa em ciências sociais e epidemiologia. Esta discussão, viva nos artigos seguintes, transmite esta impressão ao leitor: há, diante das diferenças epidemiológicas e de políticas de saúde reprodutiva das populações étnicas, uma velada eugenia? Trata-se de diferenças de posição de classe? Trata-se de diferenças relacionadas à interseção de fato-res estritamente biológicos com o meio sócio-ambiental? Para quem lê o livro organizado por Simone Monteiro e Livio Sansone fica a sugestão de que nenhum dos aspectos expostos pode ser tomado separadamente, o que chama atenção, por sua vez, para o problema da interação entre esses diversos fatores ou modelos explicativos.

Ainda nesse segmento, vale chamar a atenção para o artigo de Mônica Grin, especialmente para o debate que a historiadora estabelece com Fátima Oliveira, também com artigo na coletânea. Para Grin, há uma espécie de descompasso entre a visão dos movimentos sociais - cuja proposta geral passa pela aceitação da existência de um rígido sistema racial, que alimentaria o racismo nas relações sociais, e que deveria ser equacionado mediante políticas públicas compensatórias - e certa visão quase idílica das relações raciais no país, pela qual a idéia de democracia racial ganharia corpo, e que, em maior ou menor grau, tanto o Estado como as populações alimentariam.

Ao ler essa sessão, talvez um leitor leigo, mas atento, não se convença plenamente de que a 'raça' é um elemento analítico explicativo das diferenças de comportamento e das políticas de saúde reprodutiva, mas sim a 'classe social'. Esta impressão, justificada ou não, talvez aponte para a necessidade de maior refinamento conceitual nesse campo -, para o qual esse livro vem contribuir decisivamente. 